\title{
The
}

AERONAUTICAL JOURNAL
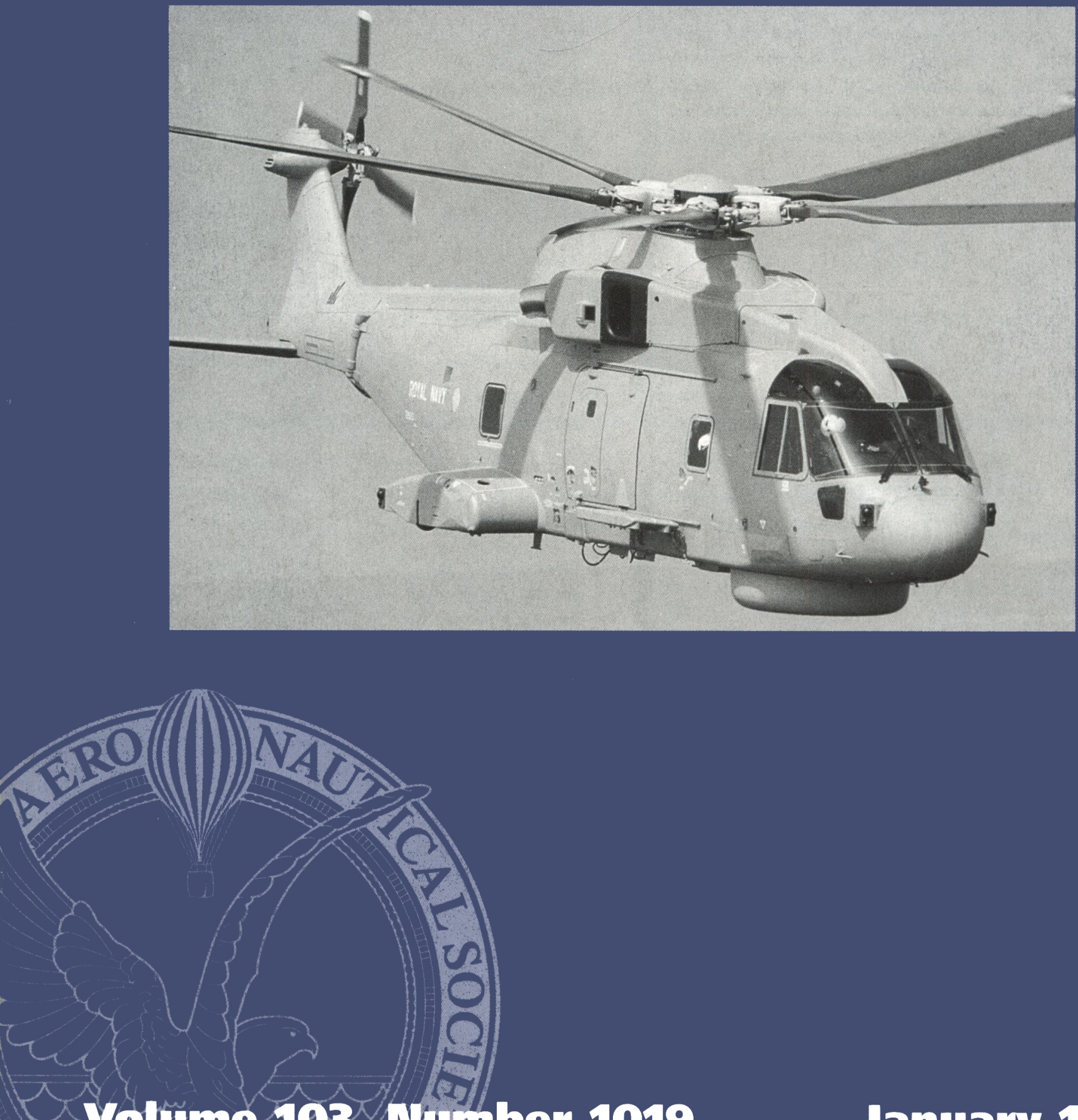

Voltume 103 , I U J ber 1019

January 1999

गत) 


\section{Aims and scope}

The aims and scope of The Aeronautical Journal are intended to reflect the objectives of the Royal Aeronautical Society as expressed in its Charter of Incorporation. Briefly, these are to encourage and foster the advancement of all aspects of aeronautical and space science. Thus the topics of the Journal include most of those covered by the various Sections and Groups of the Society, such as aerodynamics (including fluid mechanics), astronautics, dynamics and control, flight simulation, guided flight, noise and vibration, propulsion, rotorcraft, structures and materials, systems and test procedures. Papers are therefore solicited on all aspects of research, design and development, construction and operation of aircraft and space vehicles. Papers are also welcomed which review, comprehensively, the results of recent research developments in any of the above topics.

\section{Editorial Advisory Committee Chairman: Dr Eric Rogers Editor: Prof John Stollery \\ Aerodynamics \\ Prof Peter Bearman \\ Tony Cross \\ Head of Department, Department of Aeronautics, Imperial College, London \\ Manager - Aerodynamic Technology \\ BAe Military Aircraft and Aerostructures \\ Avionics/Simulation \\ Prof David Allerton Head, Department of Avionics. \\ College of Aeronautics, Cranfield University \\ Materials \\ Dr Mike Hicks \\ Propulsion \\ Dr Peter Stow \\ Head of Materials, Rolls-Royce Aerospace Group \\ Head of Aerothermal Methods, \\ Rolls-Royce Aerospace Group \\ Rotorcraft \\ Alan Vincent \\ Dr Gareth Padfield \\ Head of Engineering, GKN Westland Helicopters Head of Rotorcraft Group, Flight Dynamics and Simulation Group, DERA Bedford \\ Space \\ Roy Gibson \\ Former Director General of the \\ European Space Agency \\ Structures \\ Prof Glyn Davies \\ Head of Aerostructures, Department of \\ Aeronautics, Imperial College, London \\ Systems \\ Prof Donald McLean Professor of Flight Control, Department of Aeronautical and Astronautics, \\ University of Southampton \\ Testing \\ Dr Graham Coleman Chief Scientist (Aircraft Systems), DERA Farnborough}

\section{Subscriptions}

\section{The Aeronautical Journal}

\section{Non-members}

Annual subscription (12 issues)

Single copies, including back issues

From: The Royal Aeronautical Society

Publications Subscriptions Department

Bradiey Pavilions

Bradley Stoke North

Bristol BSI2 0BO. UK

Tel: +44 (0) | 454620070 Fax: +44(0) | 454620080

\section{RAeS members}

Annual subscription ( 12 issues)

Single copies, including back issues

From: The Professional Affairs Department

The Royal Aeronautical Society

4 Hamilton Place

London WIV OBQ, UK

Tel: +44 (0) I7| 4993515 Fax: +44 (0) |7| 4996230

e-mail: professional@raes.org.uk

\section{RAeS Conference Proceedings}

Details, price and availability of Royal Aeronautical Society Conference Proceedings can be obtained from:

The Conference Department

The Royal Aeronautical Society

4 Hamilton Place

London WIV OBQ, UK

Tel: +44 (0) 17| 4993515 Fax: +44 (0) 17| 493 I438

e-mail: conference@raes.org.uk

\section{Submissions}

To submit a paper to The Aeronautical Journal, THREE printed manuscripts along with figures (of high quality) should be sent to the Editor at

\section{The Royal Aeronautical Society \\ 4 Hamilton Place \\ London WIV OBQ \\ United Kingdom}

For further advice on submitting papers to The Aeronautical Journal, please refer to the Guidance for Authors on page iv. If previously agreed with the editorial staff, it may be possible to supply a paper in a different format.

The Royal Aeronautical Society reserves the right to reject a paper which is not submitted in the required manner. 


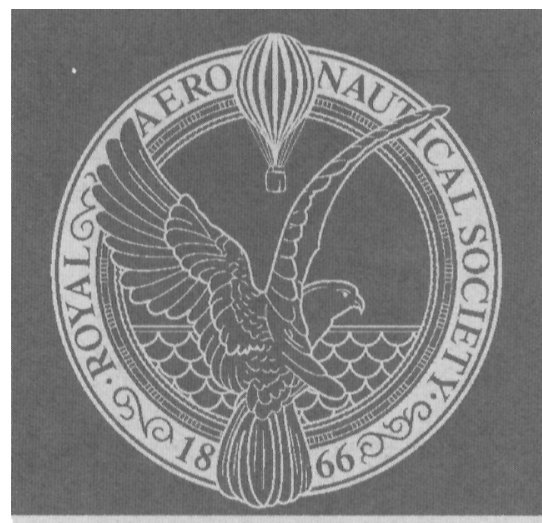

\section{Contents}

Volume 103, Number 1019

Reproduction of any of the papers published in this journal is not permitted without the written consent of the Editor.

Editor

Professor J L Stollery CBE DSc(Eng) FEng FAIAA HonfRAeS

Managing Editor

I R Sheppard BEng(Hons) GradRAeS

Deputy Editor

C S C Male BSc(Eng) MRAeS

Production Assistants

M) Wagland BA(Hons)

G T Corsi BEng(Hons) GradRAeS

Publisher

The Royal Aeronautical Society (RAeS)

4 Hamilton Place

London WIV OBQ

Tel: $+44(0) 1714993515$

Fax: +44 (0)171 6294009

e-mail: raes@raes.org.uk

publications@raes.org.uk

http://www.raes.org.uk

The Royal Aeronautical Society

is a registered charity: No 313708

RAeS Director

KD R Mans BA FRAeS

The content does not necessarily express the opinion of the Council of the Royal Aeronautical Society.

\section{Advertisement Sales}

David Holmes, Advertisement Sales Director

The Media Centre

East Rudham

King's Lynn

Norfolk PE3I 8RD

United Kingdom

Tel: $+44(0) \mid 485528020$

Fax: +44 (0) 1485528022

e-mail: Igmedia@aol.com

\section{Subscriptions}

See left

\section{Printers}

Manor Park Press

Unit 7 Highfield Industrial Estate

Edison Road

Hampden Park

Eastbourne BS32 OPP

United Kingdom

ISSN: $0001-9240$

Published monthly

\section{D.G. Mabey}

Unsteady aerodynamics: retrospect and prospect

J.M. Délery

Shock phenomena in high speed aerodynamics: still a source of major concern

S.T. Shaw and N. Qin

Unsteady flow around helicopter rotor blade sections in forward flight

\section{$X$. Zhang and J.A. Edwards}

Pressure over a two-cavity cascade at supersonic speeds

J.G. Jones, G.D. Padfield and M.T. Charlton

Wavelet analysis of pilot workload in helicopter low-level flying tasks 
Papers will be considered for publication in The Aeronautical Journal if they meet the terms and conditions below. If these are not met, the Editor reserves the right to withdraw the paper without redress, which may be at any time up to publication.

\subsection{PREPARATION OF PAPERS}

\subsection{General}

For a paper to be considered, three clearly typed (double spaced) copies must be sent to the Editor with photocopies of figures (including any photographs) if not included within the printed text. Handwritten manuscripts are not acceptable. The accompanying letter must state that the paper has not been published previously or submitted for publication elsewhere.

The receipt of papers will be acknowledged by return, with a copy of these conditions and a reference number which should be used in all correspondence

Prior to submission, manuscripts should be read critically by a third party who is familiar with the subject area and has a good grasp of the English language. Authors must also obtain permission where necessary to use any material in a paper which is copyright or the property of any other persons or entity, including their employers. Any fees incurred are the sole responsibility of the authors.

\subsection{Figures}

All figures must be provided by the authors. Illustrations should be kept to a minimum and should, where appropriate, be produced to the same scale. A list of figures helps in the production of the paper.

\subsection{Full paper format}

Formal papers should comply with the structural guidelines below and should preferably not exceed 10000 words. The following is the recommended generic format:

Title: The title should be kept short and concise.

Abstract: A single paragraph abstract of around 150 words which summarises the paper and contains no references.

Nomenclature: A list of all symbols used in the text and figures, whether familiar or not, should be given in alphabetical order, with for example c before C, and all English letters listed before Greek symbols. Subscripts and Superscripts should, where possible, be listed separately. SI units should be used throughout and are thus not required to be shown here.

\section{MAIN TEXT}

1. Introduction: Discuss the raison d'etre of the work, including previous work by others and how the work being presented aims to advance or complement this.

2. Descriptive section: This could be either description of apparatus if an experimental paper, or a discussion of the practical applications if a more theoretical paper.

3. Theoretical section: Equations should be numbered in the order given and referred to in the text by number as, for example, Equation (19). Complex groupings should not be included in text, but should be numbered as equations.

4. Procedural section: Describe the procedure which utilises that described in (2) above.

5. Presentation and discussion of results: Tables of results, numbered in order, should be referred to here, and should include only the main results. Errors should be considered an important part of any analysis.

6. Conclusions: This section should be very concise, and bullet points are recommended for clarity. The degree to which the aims have been achieved should be clearly portrayed to the reader. Suggestions for future work or work in progress are encouraged.

References: References should be numbered sequentially in the text as they occur. For example, most commonly for papers (1) and reports(2)

1. Miller, $P$ and Wilson, M. Wall jets created by single and twin high pressure jet impingement, Aeronaut J, March 1993, 97, (963), pp 87-100.

2. Green, J.E., Weeks, D.J. and Brooman, J.W.F. Prediction of turbulent boundary layers and wakes in compressible flow, ARC R\&M No 3791, 1979

and for books ${ }^{(3)}$

3. King-Hele, D. Satellite Orbits in an Atmosphere, Blackie, Glasgow, 1987.

Appendices: If no suitable reference is available appendices may be used to clarify certain points, such as a step in the theoretical analysis.

\subsection{Technical Notes}

These can be up to 2000 words in length and have no set form. They can be abstracts, comments upon unpublished papers, notes on interim results or a prompt for further research. They do not have to contain figures or nomenclature and may be in the form of a letter.

\subsection{Engineering Notes}

These are a maximum of one page and may be used to communicate practical solutions to problems encountered on the shop floor or in the laboratory

\subsection{THE REFEREEING PROCESS}

\subsection{Initial refereeing}

Two referees are used for a paper: one for a Technical or Engineering Note. One copy of the manuscript is sent to each referee with a referee report form and a request that the referee reply within six weeks or suggest an alternative referee. Hence, in some cases, delays may occur in finding a referee with suitable experience who is willing to review the paper. Authors may, if they wish, provide a list of suitably qualified independent referees to aid this process.

\subsection{Revising the paper}

Once both referees have replied, their comments are sent to the authors who are invited to revise the paper as suggested. It is helpful if a list of those changes included by the author is provided

A paper will be rejected at this stage only if this is suggested by both referees. Authors are reminded that the process is confidential, and that only referees of the highest calibre are used.

\subsection{Secondary refereeing}

Unless a paper has been accepted "as is" by both referees, a revised manuscript will be sent once more to the referees, with another report form. If the Editor feels, having considered the second reviews, that the authors have not adequately responded to the original reviews of the referees, then the paper may be rejected. Thus it is imperative that all comments be addressed properly by authors. A third referee may be approached if the Editor thinks this is appropriate. The Editor ultimately reserves the right to reject a paper on grounds of quality or lack of cooperation from authors.

\subsection{Acceptance}

Once a paper is accepted, the authors will be invited to send the latest version of the text on disk, without any structure (i.e. no codes — tabs, bold, italics, embedded figures, tables, equations etc).

The positions of equations should be indicated in the saved text. Original figures should also be sent at this stage, a set being required without annotation or borders as well as one with. For computer generated figures only those in 300 dpi TIFF formal can be accepted.

The preferred format is an Ascii text file on a $3 \cdot 5^{\prime \prime}$ disk

\subsection{Following acceptance}

About one month before the cover date, authors are sent galley proofs for checking, and should keep this in mind if likely to be away during this time. Authors are jointly entitled to 50 complimentary reprints of their paper, and may order any number of additional reprints at a price subject to quotation. These will be considerably cheaper if ordered to coincide with the original print run, and in any case will not be available if ordered later than two months after the cover date.

The original manuscript, figures and disk will be returned at this time.

\section{CONDITIONS OF PUBLICATION}

Unless specifically attributed, no material in The Acronautical Joumal shall be taken to represent the opinion of the RAeS and its Council. 